\title{
Related Results to Hybrid Pair of Mappings and Applications in Bipolar Metric Spaces
}

\author{
G. N. V. Kishore $\mathbb{D},{ }^{1}$ K. P. R. Rao $\mathbb{D}^{2},{ }^{2}$ A. Sombabu, ${ }^{3}$ and R. V. N. S. Rao $\mathbb{D}^{4}$ \\ ${ }^{1}$ Department of Mathematics, SRKR Engineering College, Bhimavaram 534 204, A.P., India \\ ${ }^{2}$ Department of Mathematics, Acharya Nagarjuna University, Nagarjuna Nagar 522 510, A.P., India \\ ${ }^{3}$ Department of Mathematics, Lingayas Institute of Management and Technology, Madalavarigudem 521212, Krishna Dt., A.P., India \\ ${ }^{4}$ Department of Mathematics, College of Natural and Computational Sciences, Wollega University, East Wollega, Nekemte, Ethiopia
}

Correspondence should be addressed to R. V. N. S. Rao; rvnrepalle@wollegauniversity.edu.et

Received 14 November 2018; Accepted 5 May 2019; Published 15 May 2019

Academic Editor: Ji Gao

Copyright (C) 2019 G. N. V. Kishore et al. This is an open access article distributed under the Creative Commons Attribution License, which permits unrestricted use, distribution, and reproduction in any medium, provided the original work is properly cited.

In this paper, we introduce the concept of multivalued contraction mappings in partially ordered bipolar metric spaces and establish the existence of unique coupled fixed point results for multivalued contractive mapping by using mixed monotone property in partially ordered bipolar metric spaces. Some interesting consequences of our results are obtained.

\section{Introduction and Preliminaries}

Fixed point theory has been playing a vital role in the study of nonlinear phenomena. The Banach fixed point theorem or contraction mapping principle was proved by Banach [1] in 1922. Turinici [2] extended the Banach contraction principle in the setting of partially ordered sets and laid the foundation of a new trend in fixed point theory.

The theory of mixed monotone multivalued mappings in ordered Banach spaces was extensively investigated by $\mathrm{Y}$. Wu [3]. Existence of fixed points in ordered metric spaces was initiated by Ran and Reurings [4], and later on several authors studied the problem of existence and uniqueness of a fixed point for mappings satisfying different contractive conditions in the framework of partially ordered metric spaces ([1-27] and references therein).

In [19], Bhaskar and Lakshmikantham introduced the concept of coupled fixed point and proved some coupled fixed point theorems in partially ordered metric spaces (see also [1-27] for more works). The study of fixed points for multivalued contraction mappings using the Hausdorff metric was initiated by Markin [20]. Later, many authors established hybrid fixed point theorems and gave applications of their results (see also [21-24]).
Very recently, in 2016 Mutlu and Gürdal [25] introduced the notion of bipolar metric spaces. Also they investigated some fixed point and coupled fixed point results on this space (see $[25,26])$.

This paper aims to introduce some coupled fixed point theorems for a multivalued mappings satisfying various contractive conditions defined on partially ordered bipolar metric spaces. We have illustrated the validity of the hypotheses of our results.

First we recall some basic definitions and results.

Definition 1 ([25]). Let $A$ and $B$ be two nonempty sets. Suppose that $d: A \times B \longrightarrow[0, \infty)$ is a mapping satisfying the following properties:

$$
\begin{aligned}
& \left(B_{0}\right) d(a, b)=0 \text { if and only if } a=b \text { for all }(a, b) \in A \times B, \\
& \left(B_{1}\right) d(a, b)=d(b, a) \text {, for all } a, b \in A \cap B, \\
& \left(B_{2}\right) d\left(a_{1}, b_{2}\right) \leq d\left(a_{1}, b_{1}\right)+d\left(a_{2}, b_{1}\right)+d\left(a_{2}, b_{2}\right) \text {, for all } \\
& a_{1}, a_{2} \in A, b_{1}, b_{2} \in B .
\end{aligned}
$$

Then the mapping $d$ is called a bipolar metric on the pair $(A, B)$ and the triple $(A, B, d)$ is called a bipolar metric space.

Definition 2 ([25]). Assume $\left(A_{1}, B_{1}\right)$ and $\left(A_{2}, B_{2}\right)$ as two pairs of sets. 
The function $F: A_{1} \cup B_{1} \longrightarrow A_{2} \cup B_{2}$ is said to be a covariant map, if $F\left(A_{1}\right) \subseteq A_{2}$ and $F\left(B_{1}\right) \subseteq B_{2}$ and denote this as $F:\left(A_{1}, B_{1}\right) \rightrightarrows\left(A_{2}, B_{2}\right)$.

The mapping $F: A_{1} \cup B_{1} \longrightarrow A_{2} \cup B_{2}$ is said to be a contravariant map, if $F\left(A_{1}\right) \subseteq B_{2}$ and $F\left(B_{1}\right) \subseteq A_{2}$ and denote this as $F:\left(A_{1}, B_{1}\right) \leftrightharpoons\left(A_{2}, B_{2}\right)$.

In particular, $d_{1}$ and $d_{2}$ are bipolar metrics in $\left(A_{1}, B_{1}\right)$ and $\left(A_{2}, B_{2}\right)$, respectively. Sometimes we use the notations $F:\left(A_{1}, B_{1}, d_{1}\right) \rightrightarrows\left(A_{2}, B_{2}, d_{2}\right)$ and $F:\left(A_{1}, B_{1}, d_{1}\right) \leftrightharpoons$ $\left(A_{2}, B_{2}, d_{2}\right)$.

Definition 3 ([25]). Let $(A, B, d)$ be a bipolar metric space. A point $v \in A \cup B$ is said to be left point if $v \in A$, a right point if $v \in B$, and a central point if both.

Similarly, a sequence $\left\{a_{n}\right\}$ on the set $A$ and a sequence $\left\{b_{n}\right\}$ on the set $B$ are called a left and right sequence, respectively.

In a bipolar metric space, sequence is the simple term for a left or right sequence.

A sequence $\left\{v_{n}\right\}$ is convergent to a point $v$ if and only if $\left\{v_{n}\right\}$ is a left sequence, $v$ is a right point, and $\lim _{n \rightarrow \infty} d\left(v_{n}, v\right)=0$; or $\left\{v_{n}\right\}$ is a right sequence, $v$ is a left point, and $\lim _{n \rightarrow \infty} d\left(v, v_{n}\right)=0$.

A bisequence $\left(\left\{a_{n}\right\},\left\{b_{n}\right\}\right)$ on $(A, B, d)$ is sequence on the set $A \times B$. If the sequences $\left\{a_{n}\right\}$ and $\left\{b_{n}\right\}$ are convergent, then the bisequence $\left(\left\{a_{n}\right\},\left\{b_{n}\right\}\right)$ is said to be convergent. $\left(\left\{a_{n}\right\},\left\{b_{n}\right\}\right)$ is Cauchy sequence, if $\lim _{n, m \rightarrow \infty} d\left(a_{n}, b_{m}\right)=0$. In a bipolar metric space, every convergent Cauchy bisequence is biconvergent.

A bipolar metric space is called complete, if every Cauchy bisequence is convergent, hence biconvergent.

Now we give our main results.

\section{Main Results}

The following definitions and results will be needed in the sequel.

Let $(A, B, d)$ be a bipolar metric space. For points $a \in$ $A, b \in B$ and the subsets $X \subseteq A, Y \subseteq B$, consider the bipolar metric $d(a, Y)=\inf \{d(a, y) / y \in Y\}$ and $d(X, b)=$ $\inf \{d(x, b) / x \in X\}$. We denote by $C B(A)$ and $C B(B)$ a class of all nonempty closed and bounded subsets of $A$ and $B$, respectively. Also denote $A^{2}=A \times A$ and $B^{2}=B \times B$. Let $H$ be the Hausdorff bipolar metric induced by the bipolar metric $d$ on $(A, B)$; that is,

$$
H(X, Y)=\max \left\{\sup _{x \in X} d(x, B), \sup _{y \in Y} d(A, y)\right\},
$$

for every $X \in C B(A)$ and $Y \in C B(B)$.

Definition 4. Let $F: A^{2} \cup B^{2} \longrightarrow C B(A \cup B)$ be given the mapping; an element $(a, b) \in A^{2} \cup B^{2}$ is called a coupled fixed point of a set valued mapping $F$ if $a \in F(a, b)$ and $b \in F(b, a)$.

Lemma 5 ([21]). Let $\kappa \geq 0$. If $X \in C B(A), Y \in C B(B)$ with $H(X, Y) \leq \kappa$, then, for each $x \in X$, there exists an element $y \in Y$ such that $d(x, y) \leq \kappa$.
Definition 6. Let $(A, B, \leq)$ be a partially ordered set and let $F$ : $\left(A^{2}, B^{2}\right) \rightrightarrows C B(A, B)$ be covariant map. We say that $F$ has the mixed monotone property if $F$ is monotone-nondecreasing in its first argument $a$ and is monotone-nonincreasing in its second argument $b$, that is, for any $(a, b) \in A^{2} \cup B^{2}$.

$$
\begin{array}{ll}
\left(a_{1}, a_{2}\right) \in A^{2}, & a_{1} \leq a_{2} \Longrightarrow F\left(a_{1}, b\right) \leq F\left(a_{2}, b\right) \\
\left(b_{1}, b_{2}\right) \in B^{2}, & b_{1} \leq b_{2} \Longrightarrow F\left(a, b_{1}\right) \geq F\left(a, b_{2}\right)
\end{array}
$$

Note that if $a_{1} \leq a_{2}, b_{1} \geq b_{2}$, and $F$ has mixed monotone property, by Definition 6 , we obtain $F\left(a_{1}, b_{1}\right) \leq F\left(a_{2}, b_{2}\right)$ and $F\left(b_{1}, a_{1}\right) \geq F\left(b_{2}, a_{2}\right)$.

Theorem 7. Let $(A, B, \leq)$ be a partially ordered set such that there exists a bipolar metric $d$ on $(A, B)$ with $(A, B, d)$ being complete bipolar metric spaces. Consider the covariant mapping $F:\left(A^{2}, B^{2}\right) \rightrightarrows C B(A, B)$ satisfying the following condition:

$$
H(F(a, b), F(p, q)) \leq \mu d(a, p)+\kappa d(b, q)
$$

for all $a, b \in A, p, q \in B$, and $\mu, \kappa$ are nonnegative constants with $a \geq p$ and $b \leq q$. And $\mu+\kappa<1$.

(7.1) F has a mixed monotone property

(7.2) There exists $\left(a_{0}, b_{0}\right) \in A^{2} \cup B^{2}$ and, for some $a_{1} \in$ $F\left(a_{0}, b_{0}\right), b_{1} \in F\left(b_{0}, a_{0}\right)$, we have $a_{0} \leq a_{1}$ and $b_{0} \geq b_{1}$

(7.3) If a nondecreasing sequence $\left(\left\{a_{n}\right\},\left\{p_{n}\right\}\right)$ is convergent to $(p, a)$ for $a \in A, p \in B$, then $a_{n} \leq p, p_{n} \leq a$ for all $n$ and if a nonincreasing sequence $\left(\left\{b_{n}\right\},\left\{q_{n}\right\}\right)$ is convergent to $(q, b)$ for $b \in A, q \in B$, then $b_{n} \geq q$, $q_{n} \geq b$ for all $n$

Then $F$ has a coupled fixed point.

Proof. Let $a_{0}, b_{0} \in A$ and $p_{0}, q_{0} \in B$. Consider the sequences $\left\{a_{n}\right\},\left\{b_{n}\right\},\left\{p_{n}\right\}$ and $\left\{q_{n}\right\}$ such that $a_{1} \in F\left(a_{0}, b_{0}\right), b_{1} \in F\left(b_{0}, a_{0}\right)$ and $p_{1} \in F\left(p_{0}, q_{0}\right), q_{1} \in F\left(q_{0}, p_{0}\right)$. By (7.2), we have that $a_{0} \leq$ $p_{1}$ and $b_{0} \geq q_{1}$ and $p_{0} \leq a_{1}$ and $q_{0} \geq b_{1}$, where $a_{1}, b_{1} \in A$ and $p_{1}, q_{1} \in B$.

Applying this in inequality (3), we have

$$
H\left(F\left(a_{0}, b_{0}\right), F\left(p_{1}, q_{1}\right)\right) \leq \mu d\left(a_{0}, p_{1}\right)+\kappa d\left(b_{0}, q_{1}\right)
$$

and

$$
H\left(F\left(b_{0}, a_{0}\right), F\left(q_{1}, p_{1}\right)\right) \leq \mu d\left(b_{0}, q_{1}\right)+\kappa d\left(a_{0}, p_{1}\right) .
$$

On adding (4) and (5), we get

$$
\begin{aligned}
& H\left(F\left(a_{0}, b_{0}\right), F\left(p_{1}, q_{1}\right)\right)+H\left(F\left(b_{0}, a_{0}\right), F\left(q_{1}, p_{1}\right)\right) \\
& \quad \leq(\mu+\kappa)\left(d\left(a_{0}, p_{1}\right)+d\left(b_{0}, q_{1}\right)\right)
\end{aligned}
$$

On the other hand

$$
H\left(F\left(a_{1}, b_{1}\right), F\left(p_{0}, q_{0}\right)\right) \leq \mu d\left(a_{1}, p_{0}\right)+\kappa d\left(b_{1}, q_{0}\right)
$$

and

$$
H\left(F\left(b_{1}, a_{1}\right), F\left(q_{0}, p_{0}\right)\right) \leq \mu d\left(b_{1}, q_{0}\right)+\kappa d\left(a_{1}, p_{0}\right)
$$


On adding (7) and (8), we get

$$
\begin{aligned}
& H\left(F\left(a_{1}, b_{1}\right), F\left(p_{0}, q_{0}\right)\right)+H\left(F\left(b_{1}, a_{1}\right), F\left(q_{0}, p_{0}\right)\right) \\
& \quad \leq(\mu+\kappa)\left(d\left(a_{1}, p_{0}\right)+d\left(b_{1}, q_{0}\right)\right)
\end{aligned}
$$

Moreover,

$$
H\left(F\left(a_{0}, b_{0}\right), F\left(p_{0}, q_{0}\right)\right) \leq \mu d\left(a_{0}, p_{0}\right)+\kappa d\left(b_{0}, q_{0}\right)
$$

and

$$
H\left(F\left(b_{0}, a_{0}\right), F\left(q_{0}, p_{0}\right)\right) \leq \mu d\left(b_{0}, q_{0}\right)+\kappa d\left(a_{0}, p_{0}\right)
$$

On adding (10) and (11), we get

$$
\begin{aligned}
& H\left(F\left(a_{0}, b_{0}\right), F\left(p_{0}, q_{0}\right)\right)+H\left(F\left(b_{0}, a_{0}\right), F\left(q_{0}, p_{0}\right)\right) \\
& \quad \leq(\mu+\kappa)\left(d\left(a_{0}, p_{0}\right)+d\left(b_{0}, q_{0}\right)\right)
\end{aligned}
$$

Also, if $d\left(a_{0}, p_{1}\right)=d\left(b_{0}, q_{1}\right)=0$, then $a_{0}=p_{1} \epsilon$ $F\left(p_{0}, q_{0}\right), b_{0}=q_{1} \in F\left(q_{0}, p_{0}\right)$. If $d\left(a_{1}, p_{0}\right)=d\left(b_{1}, q_{0}\right)=0$, then $p_{0}=a_{1} \in F\left(a_{0}, b_{0}\right), q_{0}=b_{1} \in F\left(b_{0}, a_{0}\right)$. If $d\left(a_{0}, p_{0}\right)=$ $d\left(b_{0}, q_{0}\right)=0$, then $a_{0}=p_{0}, b_{0}=q_{0}$.

It follows that $\left(a_{0}, b_{0}\right)$ is a coupled fixed point of $F$.

Assume that either $d\left(a_{0}, p_{1}\right) \neq 0$ or $d\left(b_{0}, q_{1}\right) \neq 0$ and $d\left(a_{1}, p_{0}\right) \neq 0$ or $d\left(b_{1}, q_{0}\right) \neq 0$; also $d\left(a_{0}, p_{0}\right) \neq 0$ or $d\left(b_{0}, q_{0}\right) \neq$ 0 .

Since $a_{1} \in F\left(a_{0}, b_{0}\right), b_{1} \in F\left(b_{0}, a_{0}\right)$, then from (6) and Lemma 5 there exist $p_{2} \in F\left(p_{1}, q_{1}\right), q_{2} \in F\left(q_{1}, p_{1}\right)$ such that

$$
\begin{aligned}
& d\left(a_{1}, p_{2}\right)+d\left(b_{1}, q_{2}\right) \\
& \quad \leq(\mu+\kappa)\left(d\left(a_{0}, p_{1}\right)+d\left(b_{0}, q_{1}\right)\right)
\end{aligned}
$$

and since $p_{1} \in F\left(p_{0}, q_{0}\right), q_{1} \in F\left(q_{0}, p_{0}\right)$, then from (9) and Lemma 5 there exist $a_{2} \in F\left(a_{1}, b_{1}\right), b_{2} \in F\left(b_{1}, a_{1}\right)$ such that

$$
\begin{aligned}
& d\left(a_{2}, p_{1}\right)+d\left(b_{2}, q_{1}\right) \\
& \quad \leq(\mu+\kappa)\left(d\left(a_{1}, p_{0}\right)+d\left(b_{1}, q_{0}\right)\right)
\end{aligned}
$$

Also since $a_{1} \in F\left(a_{0}, b_{0}\right), b_{1} \in F\left(b_{0}, a_{0}\right)$ and $p_{1} \in F\left(p_{0}, q_{0}\right)$, $q_{1} \in F\left(q_{0}, p_{0}\right)$, from (12) and Lemma 5 then we have

$$
\begin{aligned}
& d\left(a_{1}, p_{1}\right)+d\left(b_{1}, q_{1}\right) \\
& \quad \leq(\mu+\kappa)\left(d\left(a_{0}, p_{0}\right)+d\left(b_{0}, q_{0}\right)\right)
\end{aligned}
$$

Since, $a_{0} \leq p_{1}, b_{0} \geq q_{1}$ and $p_{0} \leq a_{1}, q_{0} \geq b_{1}, a_{1} \in$ $F\left(a_{0}, b_{0}\right), p_{1} \in F\left(p_{0}, q_{0}\right), b_{1} \in F\left(b_{0}, a_{0}\right), q_{1} \in F\left(q_{0}, p_{0}\right)$ and $a_{2} \in F\left(a_{1}, b_{1}\right), p_{2} \in F\left(p_{1}, q_{1}\right), b_{2} \in F\left(b_{1}, a_{1}\right), q_{2} \in F\left(q_{1}, p_{1}\right)$, by assumption (7.1), we get

$$
\begin{aligned}
& a_{1} \leq p_{2}, \\
& b_{1} \geq q_{2}
\end{aligned}
$$

and $p_{1} \leq a_{2}$,

$$
q_{1} \geq b_{2} \text {. }
$$

Similarly from (3) and above, we have

$$
\begin{aligned}
& d\left(a_{2}, p_{3}\right)+d\left(b_{2}, q_{3}\right) \\
& \quad \leq(\mu+\kappa)\left(d\left(a_{1}, p_{2}\right)+d\left(b_{1}, q_{2}\right)\right)
\end{aligned}
$$

and

$$
d\left(a_{3}, p_{2}\right)+d\left(b_{3}, q_{2}\right) \leq(\mu+\kappa)\left(d\left(a_{2}, p_{1}\right), d\left(b_{2}, q_{1}\right)\right)
$$

and also

$$
d\left(a_{2}, p_{2}\right)+d\left(b_{2}, q_{2}\right) \leq(\mu+\kappa)\left(d\left(a_{1}, p_{1}\right), d\left(b_{1}, q_{1}\right)\right)
$$

Since, we have $a_{1} \leq p_{2}, b_{1} \geq q_{2}$ and $p_{1} \leq a_{2}, q_{1} \geq b_{2}, a_{2} \in$ $F\left(a_{1}, b_{1}\right), p_{2} \in F\left(p_{1}, q_{1}\right), b_{2} \in F\left(b_{1}, a_{1}\right), q_{2} \in F\left(q_{1}, p_{1}\right)$ and $a_{3} \in F\left(a_{2}, b_{2}\right), p_{3} \in F\left(p_{2}, q_{2}\right), b_{3} \in F\left(b_{2}, a_{2}\right), q_{3} \in F\left(q_{2}, p_{2}\right)$. Again, applying our assumption (7.1), we get

$$
\begin{aligned}
& a_{2} \leq p_{3} \\
& b_{2} \geq q_{3} \\
& p_{2} \leq a_{3} \\
& q_{2} \geq b_{3}
\end{aligned}
$$$$
\text { and } p_{2} \leq a_{3} \text {, }
$$

Continuing similarly this process, we have $a_{n+1} \in F\left(a_{n}, b_{n}\right)$, $p_{n+1} \in F\left(p_{n}, q_{n}\right), b_{n+1} \in F\left(b_{n}, a_{n}\right), q_{n+1} \in F\left(q_{n}, p_{n}\right)$ with

$$
\begin{aligned}
& a_{n} \leq p_{n+1}, \\
& b_{n} \geq q_{n+1}
\end{aligned}
$$

and $p_{n} \leq a_{n+1}$,

$$
q_{n} \geq b_{n+1}
$$

such that

$$
\begin{aligned}
& d\left(a_{n}, p_{n+1}\right)+d\left(b_{n}, q_{n+1}\right) \\
& \quad \leq(\mu+\kappa)\left(d\left(a_{n-1}, p_{n}\right)+d\left(b_{n-1}, q_{n}\right)\right)
\end{aligned}
$$

and

$$
\begin{aligned}
& d\left(a_{n+1}, p_{n}\right)+d\left(b_{n+1}, q_{n}\right) \\
& \quad \leq(\mu+\kappa)\left(d\left(a_{n}, p_{n-1}\right)+d\left(b_{n}, q_{n-1}\right)\right)
\end{aligned}
$$

and also

$$
\begin{aligned}
& d\left(a_{n}, p_{n}\right)+d\left(b_{n}, q_{n}\right) \\
& \quad \leq(\mu+\kappa)\left(d\left(a_{n-1}, p_{n-1}\right)+d\left(b_{n-1}, q_{n-1}\right)\right)
\end{aligned}
$$

Put $t_{n}=d\left(a_{n}, p_{n+1}\right)+d\left(b_{n}, q_{n+1}\right)$ for any $n \in N$; then

$$
t_{n} \leq(\mu+\kappa)\left(t_{n-1}\right)
$$

Put $s_{n}=d\left(a_{n+1}, p_{n}\right)+d\left(b_{n+1}, q_{n}\right)$ for any $n \in N$; then

$$
s_{n} \leq(\mu+\kappa)\left(s_{n-1}\right)
$$

Put $r_{n}=d\left(a_{n}, p_{n}\right)+d\left(b_{n}, q_{n}\right)$ for any $n \in N$; then

$$
r_{n} \leq(\mu+\kappa)\left(r_{n-1}\right)
$$


Therefore $\left\{t_{n}\right\},\left\{s_{n}\right\}$, and $\left\{r_{n}\right\}$ are nonincreasing sequences. From (25), (26), and (27) we have that

$$
\begin{aligned}
& \lim _{n \longrightarrow \infty} t_{n}=0, \\
& \lim _{n \longrightarrow \infty} s_{n}=0
\end{aligned}
$$

$$
\text { and } \lim _{n \longrightarrow \infty} r_{n}=0
$$

which implies that

$$
\begin{gathered}
\lim _{n \longrightarrow \infty} d\left(a_{n}, p_{n+1}\right)=\lim _{n \longrightarrow \infty} d\left(b_{n}, q_{n+1}\right)=0, \\
\lim _{n \longrightarrow \infty} d\left(a_{n+1}, p_{n}\right)=\lim _{n \longrightarrow \infty} d\left(b_{n+1}, q_{n}\right)=0, \\
\lim _{n \longrightarrow \infty} d\left(a_{n}, p_{n}\right)=\lim _{n \longrightarrow \infty} d\left(b_{n}, q_{n}\right)=0 .
\end{gathered}
$$

Using the property $\left(B_{2}\right)$, we have

$$
\begin{aligned}
d\left(a_{n}, p_{m}\right) \leq & d\left(a_{n}, p_{n+1}\right)+d\left(a_{n+1}, p_{n+1}\right)+\cdots \\
& +d\left(a_{m-1}, p_{m}\right) \\
d\left(b_{n}, q_{m}\right) \leq & d\left(b_{n}, q_{n+1}\right)+d\left(b_{n+1}, q_{n+1}\right)+\cdots \\
& +d\left(b_{m-1}, q_{m}\right)
\end{aligned}
$$

and

$$
\begin{aligned}
d\left(a_{m}, p_{n}\right) \leq & d\left(a_{m}, p_{m-1}\right)+d\left(a_{m-1}, p_{m-1}\right)+\cdots \\
& +d\left(a_{n+1}, p_{n}\right) \\
d\left(b_{m}, q_{n}\right) \leq & \left.d\left(b_{m}\right), q_{m-1}\right)+d\left(b_{m-1}, q_{m-1}\right)+\cdots \\
& +d\left(b_{n+1}, q_{n}\right)
\end{aligned}
$$

Next, we show that $\left(\left\{a_{n}\right\},\left\{p_{n}\right\}\right)$ and $\left(\left\{b_{n}\right\},\left\{q_{n}\right\}\right)$ are Cauchy bisequence in $(A, B)$ for each $n ; m \in N$ such that $n<m$. From (25), (26), (27), (30), and (31), we have

$$
\begin{aligned}
d\left(a_{n,} p_{m}\right)+d\left(b_{n}, q_{m}\right) & \\
\leq & \left(d\left(a_{n,} p_{n+1}\right)+d\left(b_{n, q_{n+1}}\right)\right) \\
& +\left(d\left(a_{n+1}, p_{n+1}\right)+d\left(b_{n+1}, q_{n+1}\right)\right)+\cdots \\
& +\left(d\left(a_{m-1}, p_{m-1}\right)+d\left(b_{m-1}, q_{m-1}\right)\right) \\
& +\left(d\left(a_{m-1}, p_{m}\right)+d\left(b_{m-1}, q_{m}\right)\right) \\
\leq & t_{n}+r_{n+1}+\cdots+t_{m-1}+r_{m-1} \\
\leq & \left(t_{n}+t_{n+1}+\cdots+t_{m-1}\right) \\
& +\left(r_{n+1}+r_{n+2}+\cdots+r_{m-1}\right) \leq \sum_{k=n}^{m-1} t_{k}+\sum_{k=n+1}^{m-1} r_{k} \\
\longrightarrow & 0 \text { as } m, n \longrightarrow \infty
\end{aligned}
$$

and

$$
\begin{aligned}
d\left(a_{m,} p_{n}\right)+d\left(b_{m}, q_{n}\right) & \\
\leq & \left(d\left(a_{m}, p_{m-1}\right)+d\left(b_{m}, q_{m-1}\right)\right) \\
& +\left(d\left(a_{m-1}, p_{m-1}\right)+d\left(b_{m-1}, q_{m-1}\right)\right)+\cdots \\
& +\left(d\left(a_{n+1}, p_{n+1}\right)+d\left(b_{n+1}, q_{n+1}\right)\right) \\
& +\left(d\left(a_{n+1}, p_{n}\right)+d\left(b_{n+1}, q_{n}\right)\right) \\
\leq & s_{m-1}+r_{m-1}+\cdots+r_{n+1}+s_{n} \\
\leq & \left(s_{n}+s_{n+1}+\cdots+s_{m-1}\right) \\
& +\left(r_{n+1}+r_{n+2}+\cdots+r_{m-1}\right) \leq \sum_{k=n}^{m-1} s_{k}+\sum_{k=n+1}^{m-1} r_{k} \\
\longrightarrow & 0 \text { as } m, n \longrightarrow \infty
\end{aligned}
$$

From above, it is clear that $\left(\left\{a_{n}\right\},\left\{p_{n}\right\}\right)$ and $\left(\left\{b_{n}\right\},\left\{q_{n}\right\}\right)$ are Cauchy bisequences in $(A, B)$. Since, $(A, B, d)$ is complete, $a, b \in A$ and $p, q \in B$ such that

$$
\begin{aligned}
& \lim _{n \longrightarrow \infty} a_{n+1}=p, \\
& \lim _{n \longrightarrow \infty} b_{n+1}=q, \\
& \lim _{n \longrightarrow \infty} p_{n+1}=a, \\
& \lim _{n \longrightarrow \infty} q_{n+1}=b
\end{aligned}
$$

Now we will show that $a \in F(a, b), b \in F(b, a)$ and $p \in F(p, q), q \in F(q, p)$. As $\left(\left\{a_{n}\right\},\left\{p_{n}\right\}\right)$ is a nondecreasing bisequence and $\left(\left\{b_{n}\right\},\left\{q_{n}\right\}\right)$ is a nonincreasing bisequence in (A, B),

$$
\begin{aligned}
a_{n} & \longrightarrow p, \\
b_{n} & \longrightarrow q \\
\text { and } p_{n} & \longrightarrow a, \\
q_{n} & \longrightarrow b .
\end{aligned}
$$

By assumption (7.1), we get $a_{n} \leq p, p_{n} \leq a$ and $b_{n} \geq q, q_{n} \geq b$ for all $n$. If $a_{n}=p, p_{n}=a$ and $b_{n}=q, q_{n}=b$ for some $n \geq 0$, then $p=a_{n} \leq p_{n+1} \leq a=p_{n} q=b_{n} \geq q_{n+1} \geq b=q_{n}$ and $a=p_{n} \leq a_{n+1} \leq p=a_{n}, b=q_{n} \geq b_{n+1} \geq q=b_{n}$ implies $a=p$ and $b=q$; therefore, $a_{n}=a_{n+1} \in F\left(a_{n}, b_{n}\right)$ and $b_{n}=b_{n+1} \in F\left(b_{n}, a_{n}\right)$.

So $\left(a_{n}, b_{n}\right)$ is coupled fixed point of $F$.

Suppose that $\left(a_{n}, p_{n}\right) \neq(p, a)$ and $\left(b_{n}, q_{n}\right) \neq(q, b)$ for all $n \geq 0$.

From (3), we have

$$
H\left(F(a, b), F\left(p_{n}, q_{n}\right)\right) \leq \mu d\left(a, p_{n}\right)+\kappa d\left(b, q_{n}\right)
$$

and

$$
H\left(F(b, a), F\left(q_{n}, p_{n}\right)\right) \leq \mu d\left(b, q_{n}\right)+\kappa d\left(a, p_{n}\right)
$$


Therefore,

$$
\begin{aligned}
H & \left(F(a, b), F\left(p_{n}, q_{n}\right)\right)+H\left(F(b, a), F\left(q_{n}, p_{n}\right)\right) \\
& \leq(\mu+\kappa)\left(d\left(a, p_{n}\right)+d\left(b, q_{n}\right)\right)
\end{aligned}
$$

Letting $n \longrightarrow \infty$, we have that

$$
\begin{aligned}
& \lim _{n \longrightarrow \infty}\left(H\left(F(a, b), F\left(p_{n}, q_{n}\right)\right)\right. \\
& \left.\quad+H\left(F(b, a), F\left(q_{n}, p_{n}\right)\right)\right)=0
\end{aligned}
$$

Since $p_{n+1} \in F\left(p_{n}, q_{n}\right)$ and $\lim _{n \rightarrow \infty} d\left(a, p_{n+1}\right)=0$, we have $a \in F(a, b)$ and since $q_{n+1} \in F\left(q_{n}, p_{n}\right)$ and $\lim _{n \rightarrow \infty} d\left(b, q_{n+1}\right)=0$, we have $b \in F(b, a)$.

Similarly, we can prove $p \in F(p, q)$ and $q \in F(q, b)$.

On the other hand,

$$
d(a, p)=d\left(\lim _{n \rightarrow \infty} p_{n}, \lim _{n \rightarrow \infty} a_{n}\right)=\lim _{n \rightarrow \infty} d\left(a_{n}, p_{n}\right)=0
$$

and

$$
d(b, q)=d\left(\lim _{n \longrightarrow \infty} q_{n}, \lim _{n \rightarrow \infty} b_{n}\right)=\lim _{n \rightarrow \infty} d\left(b_{n}, q_{n}\right)=0 .
$$

Therefore, $a=p$ and $b=g$ and hence $F$ has a coupled fixed point.

Theorem 8. Let $(A, B, \leq)$ be a partially ordered set such that there exists a bipolar metric $d$ on $(A, B)$ with $(A, B, d)$ being complete bipolar metric spaces. Consider $F:\left(A^{2}, B^{2}\right) \rightrightarrows$ $C B(A, B)$ a covariant set valued mapping, such that

$$
H(F(a, b), F(p, q)) \leq \frac{\kappa}{2}(d(a, p)+d(b, q))
$$

for all $a, b \in A, p, q \in B$, and $\kappa \in(0,1)$ with $a \geq p$ and $b \leq q$. Suppose also that

(8.1) F has a mixed monotone property

(8.2) there exist $\left(a_{0}, b_{0}\right) \in A^{2} \cup B^{2}$ and for some $a_{1} \in$ $F\left(a_{0}, b_{0}\right), b_{1} \in F\left(b_{0}, a_{0}\right)$ we have $a_{0} \leq a_{1}$ and $b_{0} \geq b_{1}$

(8.3) if a nondecreasing sequence $\left(\left\{a_{n}\right\},\left\{p_{n}\right\}\right)$ is convergent to $(p, a)$ for $a \in A, p \in B$, then $a_{n} \leq p, p_{n} \leq a$ for all $n$ and if a nonincreasing sequence $\left(\left\{b_{n}\right\},\left\{q_{n}\right\}\right)$ is convergent to $(q, b)$ for $b \in A, q \in B$, then $b_{n} \geq q$, $q_{n} \geq b$ for all $n$

Then $F$ has a coupled fixed point; that is, there exist $(a, b) \in$ $A^{2} \cup B^{2}$ such that $a \in F(a, b)$ and $b \in F(b, a)$.

Example 9. Let $A=\left\{U_{m}(R) / U_{m}(R)\right.$ be upper triangular matrices over $R\}$ and let $B=\left\{L_{m}(R) / L_{m}(R)\right.$ be lower triangular matrices over $R\}$ with the bipolar metric $d(P, Q)=$ $\sum_{i, j=1}^{m}\left|p_{i j}-q_{i j}\right|$ for all $P=\left(p_{i j}\right)_{m \times m} \in U_{m}(R)$ and $Q=$ $\left(q_{i j}\right)_{m \times m} \in L_{m}(R)$. On the set $(A, B)$, consider the following relation:

$$
(P, Q) \in A^{2} \cup B^{2}, \quad P \preceq Q \Longleftrightarrow p_{i j} \leq q_{i j}
$$

where $\leq$ is usual ordering. Then, clearly, $(A, B, d)$ is a complete bipolar metric space and $(A, B, \preceq)$ is a partially ordered set.
Let $F:\left(A^{2}, B^{2}\right) \rightrightarrows C B(A, B)$ be defined as $F(P, Q)=$ $\left(\left(p_{i j}+q_{i j}\right) / 5\right)_{m \times m}+(3 / 5)\left(I_{i j}\right)_{m \times m}$ for all $\left(P=\left(p_{i j}\right)_{m \times m}, Q=\right.$ $\left.\left(q_{i j}\right)_{m \times m}\right) \in A^{2} \cup B^{2}$.

Then obviously $F$ has mixed monotone property; also there exist $P=\left(O_{i j}\right)_{m \times m}$ and $Q=\left(I_{i j}\right)_{m \times m}$ such that

$$
\begin{aligned}
F & \left(\left(O_{i j}\right)_{m \times m},\left(I_{i j}\right)_{m \times m}\right) \\
& =\left(\frac{O_{i j}+I_{i j}}{5}\right)_{m \times m}+\frac{3}{5}\left(I_{i j}\right)_{m \times m} \geq\left(O_{i j}\right)_{m \times m}
\end{aligned}
$$

and

$$
\begin{aligned}
& F\left(\left(I_{i j}\right)_{m \times m},\left(O_{i j}\right)_{m \times m}\right) \\
& \quad=\left(\frac{O_{i j}+I_{i j}}{5}\right)_{m \times m}+\frac{3}{5}\left(I_{i j}\right)_{m \times m} \preceq\left(I_{i j}\right)_{m \times m}
\end{aligned}
$$

Taking $\left(P=\left(p_{i j}\right)_{m \times m}, Q=\left(q_{i j}\right)_{m \times m}\right),\left(R=\left(r_{i j}\right)_{m \times m}, S=\right.$ $\left.\left(s_{i j}\right)_{m \times m}\right) \in A^{2} \cup B^{2}$ with $P \geq R, Q \leq S$, that is, $p_{i j} \geq r_{i j}$, $q_{i j} \leq s_{i j}$, we have

$$
\begin{aligned}
d & (F(P, Q), F(R, S)) \\
& =d\left(\frac{p_{i j}+q_{i j}}{5}+\frac{3}{5}\left(I_{i j}\right), \frac{r_{i j}+s_{i j}}{5}+\frac{3}{5}\left(I_{i j}\right)\right) \\
& =\frac{1}{5} \sum_{i, j=1}^{m}\left|\left(p_{i j}+q_{i j}\right)-\left(r_{i j}+s_{i j}\right)\right| \\
& \leq \frac{1}{5}\left(\sum_{i, j=1}^{m}\left|p_{i j}-r_{i j}\right|+\sum_{i, j=1}^{m}\left|q_{i j}-s_{i j}\right|\right) \\
& \leq \frac{1}{5}(d(P, R)+d(Q, S))
\end{aligned}
$$

Therefore, all the conditions of Theorem 8 hold and $\left(\left((3 / 5) I_{i j}\right)_{m \times m},\left((3 / 5) I_{i j}\right)_{m \times m}\right)$ is a coupled fixed point of $F$.

Definition 10. Let $(A, B, d)$ be bipolar metric spaces, $a \in$ $A, p \in B$, and let $F:(A \times B) \cup(B \times A) \longrightarrow C B(A \cup B)$ be a covariant multivalued map. An element $(a, p)$ is called a coupled fixed point of $F$ if $a \in F(a, p)$ and $p \in F(p, a)$.

Theorem 11. Let $(A, B, \leq)$ be a partially ordered set such that there exists a bipolar metric d on $(A, B)$ with $(A, B, d)$ being complete bipolar metric spaces. Consider $F:(A \times B, B \times A) \rightrightarrows$ $C B(A, B)$ a covariant set valued mapping, such that

$$
H(F(a, p), F(q, b)) \leq \mu d(a, q)+\kappa d(b, p)
$$

for all $a, b \in A, p, q \in B$ and $\mu+\kappa<1$ with $a \geq q$ and $b \leq p$. Suppose also that

(11.1) F has a mixed monotone property

(11.2) there exist $a_{0} \in A, p_{0} \in B$ and for some $a_{1} \in F\left(a_{0}, p_{0}\right)$, $p_{1} \in F\left(p_{0}, a_{0}\right)$ we have $a_{0} \leq a_{1}$ and $p_{0} \geq p_{1}$

(11.3) if a nondecreasing sequence $\left(\left\{a_{n}\right\},\left\{q_{n}\right\}\right)$ is convergent to $(q, a)$ for $a \in A, q \in B$, then $a_{n} \leq q, q_{n} \leq$ a for all $n$ and if a nonincreasing sequence $\left(\left\{b_{n}\right\},\left\{p_{n}\right\}\right)$ is convergent to $(p, b)$ for $b \in A, p \in B$, then $b_{n} \geq p, p_{n} \geq b$ for all $n$ 
Then $F$ has a coupled fixed point; that is, there exist $a \in$ $A, p \in B$ such that $a \in F(a, p)$ and $p \in F(p, a)$.

Proof. The proof will follow when we replace $A \times B$ and $B \times A$ in place of $A^{2}, B^{2}$, respectively, in Theorem 7 .

Theorem 12. Let $(A, B, \leq)$ be a partially ordered set such that there exists a bipolar metric $d$ on $(A, B)$ with $(A, B, d)$ being complete bipolar metric spaces. Consider $F:(A \times B, B \times A) \rightrightarrows$ $C B(A, B)$ a covariant set valued mapping, such that

$$
H(F(a, p), F(q, b)) \leq \frac{\kappa}{2}(d(a, q)+d(b, p))
$$

for all $a, b \in A, p, q \in B$ and $\kappa \in(0,1)$ with $a \geq q$ and $b \leq p$. Suppose also that

\section{(12.1) F has a mixed monotone property}

(12.2) there exist $a_{0} \in A, p_{0} \in B$ and for some $a_{1} \in F\left(a_{0}, p_{0}\right)$, $p_{1} \in F\left(p_{0}, a_{0}\right)$ we have $a_{0} \leq a_{1}$ and $p_{0} \geq p_{1}$

(12.3) if a nondecreasing sequence $\left(\left\{a_{n}\right\},\left\{q_{n}\right\}\right)$ is convergent to $(q, a)$ for $a \in A, q \in B$, then $a_{n} \leq q, q_{n} \leq$ a for all $n$ and if a nonincreasing sequence $\left(\left\{b_{n}\right\},\left\{p_{n}\right\}\right)$ is convergent to $(p, b)$ for $b \in A, p \in B$, then $b_{n} \geq p, p_{n} \geq b$ for all $n$

Then $F$ has a coupled fixed point; that is, there exist $a \in$ $A, p \in B$ such that $a \in F(a, p)$ and $p \in F(p, a)$.

\section{Conclusions}

In the present research, we introduced and proved a coupled fixed point theorem for a multivalued mapping, satisfying various contractive conditions, defined on a partially ordered bipolar metric space, and gave suitable example that supports our main result.

\section{Data Availability}

No data were used to support this study.

\section{Conflicts of Interest}

The authors declare that they have no competing interest.

\section{Authors' Contributions}

All authors contributed equally and significantly in writing this article. All authors read and approved the final manuscript.

\section{References}

[1] S. Banach, "Sur les opérations dans les ensembles abstraits et leur application aux équations intégrales," Fundamenta Mathematicae, vol. 3, pp. 133-181, 1922.

[2] M. Turinici, "Abstract comparison principles and multivariable Gronwall-Bellman inequalities," Journal of Mathematical Analysis and Applications, vol. 117, no. 1, pp. 100-127, 1986.
[3] Y. Wu, "New fixed point theorems and applications of mixed monotone operator," Journal of Mathematical Analysis and Applications, vol. 341, no. 2, pp. 883-893, 2008.

[4] A. C. M. Ran and M. C. B. Reurings, "A fixed point theorem in partially ordered sets and some applications to matrix equations," Proceedings of the American Mathematical Society, vol. 132, no. 5, pp. 1435-1443, 2004.

[5] J. J. Nieto and R. Rodríguez-López, "Contractive mapping theorems in partially ordered sets and applications to ordinary differential equations," Order, vol. 22, no. 3, pp. 223-239, 2005.

[6] G. N. Kishore, R. P. Agarwal, B. Srinuvasa Rao, and R. V. Srinivasa Rao, "Caristi type cyclic contraction and common fixed point theorems in bipolar metric spaces with applications," Fixed Point Theory and Applications, 13 pages, 2018, article no. 18.

[7] B. Srinuvasa Rao, G. N. V. Kishore, and S. Ramalingeswara Rao, "Fixed point theorems under new Caristi type contraction in bipolar metric space with applications," International Journal of Engineering and Technology(UAE), vol. 7, no. 3, pp. 106-110, 2018.

[8] J. J. Nieto and R. Rodríguez-López, "Existence and uniqueness of fixed point in partially ordered sets and applications to ordinary differential equations," Acta Mathematica Sinica, vol. 23, no. 12, pp. 2205-2212, 2007.

[9] R. P. Agarwal, M. A. El-Gebeily, and D. O’Regan, "Generalized contractions in partially ordered metric spaces," Applicable Analysis: An International Journal, vol. 87, no. 1, pp. 109-116, 2008.

[10] I. Altun and H. Simsek, "Some fixed point theorems on ordered metric spaces and application," Fixed Point Theory and Applications, vol. 2010, Article ID 621469, 17 pages, 2010.

[11] W. Shatanawi, B. Samet, and M. Abbas, "Coupled fixed point theorems for mixed monotone mappings in ordered partial metric spaces," Mathematical and Computer Modelling, vol. 55, no. 3-4, pp. 680-687, 2012.

[12] A. Amini-Harandi, "Coupled and tripled fixed point theory in partially ordered metric spaces with application to initial value problem," Mathematical and Computer Modelling, vol. 57, no. 910, pp. 2343-2348, 2013.

[13] M. Mursaleen, S. A. Mohiuddine, and R. P. Agarwal, "Coupled fixed point theorems for $\alpha$ - $\psi$-contractive type mappings in partially ordered metric spaces," Fixed Point Theory and Applications, vol. 228, 2012.

[14] H. K. Nashine and B. Samet, "Fixed point results for mappings satisfying $(\psi, \phi)$-weakly contractive condition in partially ordered metric spaces," Nonlinear Analysis: Theory, Methods \& Applications, vol. 74, no. 6, pp. 2201-2209, 2011.

[15] H. Aydi, M. Abbas, and M. Postolache, "Coupled coincidence points for hybrid pair of mappings via mixed monotone property," Journal of Advanced Mathematical Studies, vol. 5, no. 1, pp. 118-126, 2012.

[16] H. Aydi, E. Karapnar, and W. Shatanawi, "Coupled fixed point results for $(\psi, \phi)$-weakly contractive condition in ordered partial metric spaces," Computers \& Mathematics with Applications, vol. 62, no. 12, pp. 4449-4460, 2011.

[17] H. Aydi, M. Abbas, and C. Vetro, "Partial Hausdorff metric and Nadler's fixed point theorem on partial metric spaces," Topology and its Applications, vol. 159, no. 14, pp. 3234-3242, 2012.

[18] H. Aydi, M. Abbas, and C. Vetro, "Common fixed points for multivalued generalized contractions on partial metric spaces," RACSAM - Revista de la Real Academia de Ciencias Exactas, 
Fsicas y Naturales. Serie A. Matematicas, vol.108, no. 2, pp. 483501, 2014.

[19] T. G. Bhaskar and V. Lakshmikantham, "Fixed point theorems in partially ordered metric spaces and applications," Nonlinear Analysis: Theory, Methods \& Applications, vol. 65, no. 7, pp. 13791393, 2006.

[20] J. T. Markin, "Continuous dependence of fixed point sets," Proceedings of the American Mathematical Society, vol. 38, pp. 545-547, 1973.

[21] S. B. Nadler, "Multi-valued contraction mappings," Pacific Journal of Mathematics, vol. 30, pp. 475-488, 1969.

[22] B. C. Dhage, "A fixed point theorem for multivalued mappings on ordered Banach spaces with applications I," Nonlinear Analysis Forum, vol. 10, no. 1, pp. 105-126, 2005.

[23] B. C. Dhage, "A general multi-valued hybrid fixed point theorem and perturbed differential inclusions," Nonlinear Analysis. Theory, Methods \& Applications. An International Multidisciplinary Journal, vol. 64, no. 12, pp. 2747-2772, 2006.

[24] S. Hong, "Fixed points of multivalued operators in ordered metric spaces with applications," Nonlinear Analysis: Theory, Methods \& Applications, vol. 72, no. 11, pp. 3929-3942, 2010.

[25] A. Mutlu and U. Gurdal, "Bipolar metric spaces and some fixed point theorems," Journal of Nonlinear Sciences and Applications. JNSA, vol. 9, no. 9, pp. 5362-5373, 2016.

[26] A. Mutlu, K. Ozkan, and U. Gurdal, "Coupled fixed point theorems on bipolar metric spaces," European Journal of Pure and Applied Mathematics, vol. 10, no. 4, pp. 655-667, 2017.

[27] L. Ćirić, B. Samet, H. Aydi, and C. Vetro, "Common fixed points of generalized contractions on partial metric spaces and an application," Applied Mathematics and Computation, vol. 218, no. 6, pp. 2398-2406, 2011. 


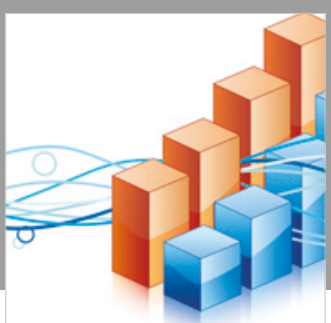

Advances in

Operations Research

\section{-n-m}
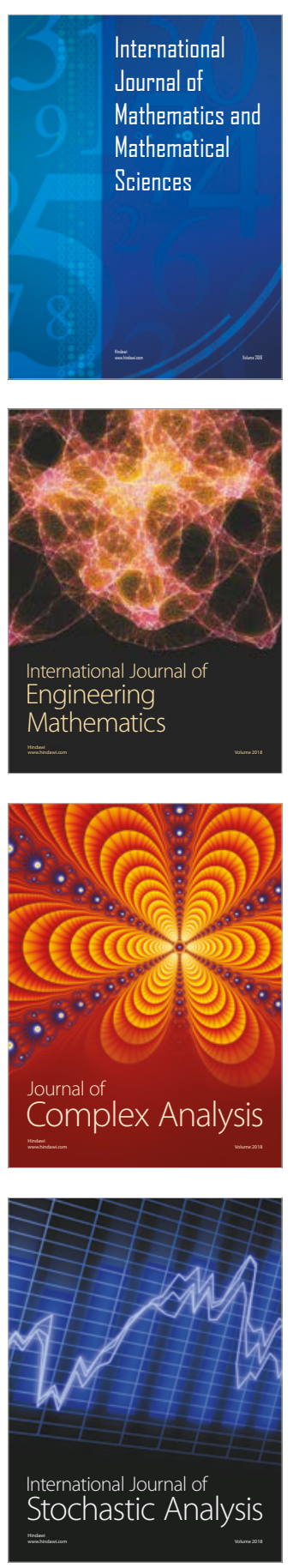
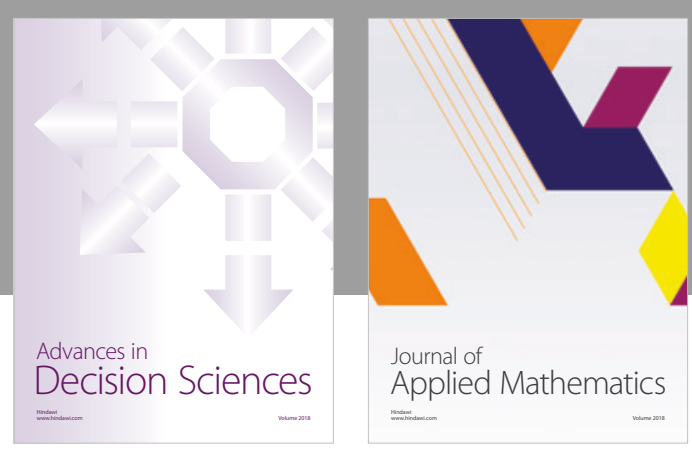

Journal of

Applied Mathematics
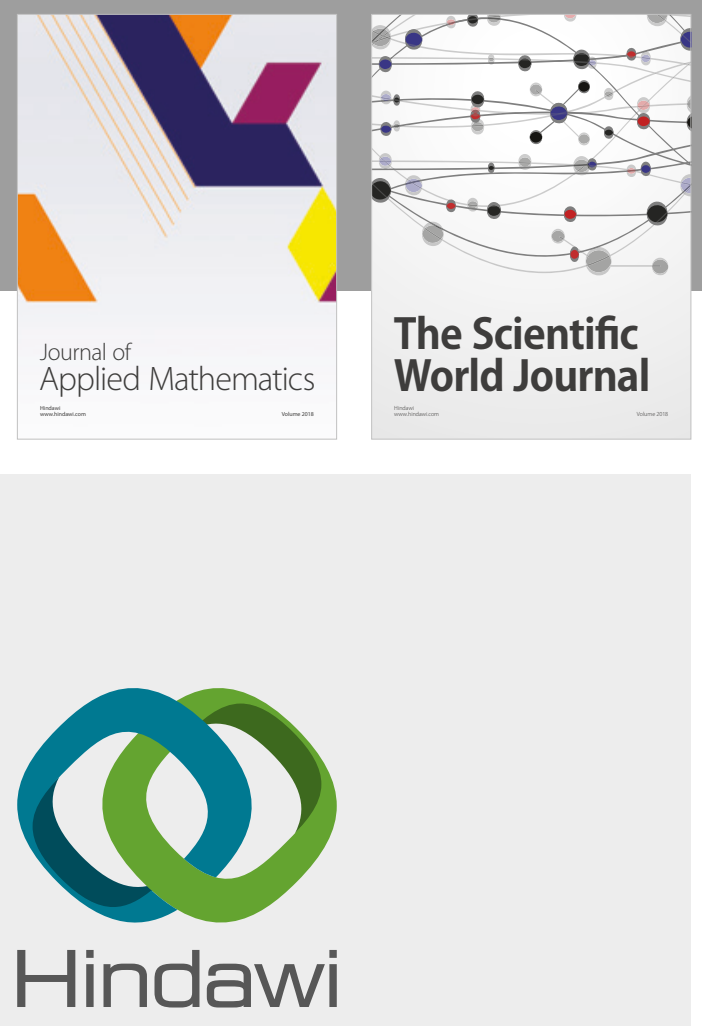

Submit your manuscripts at

www.hindawi.com

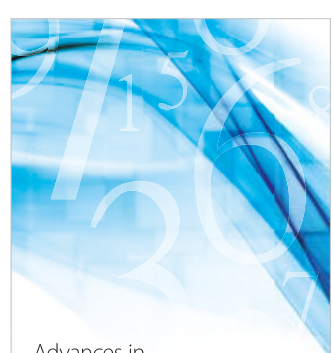

Advances in
Numerical Analysis
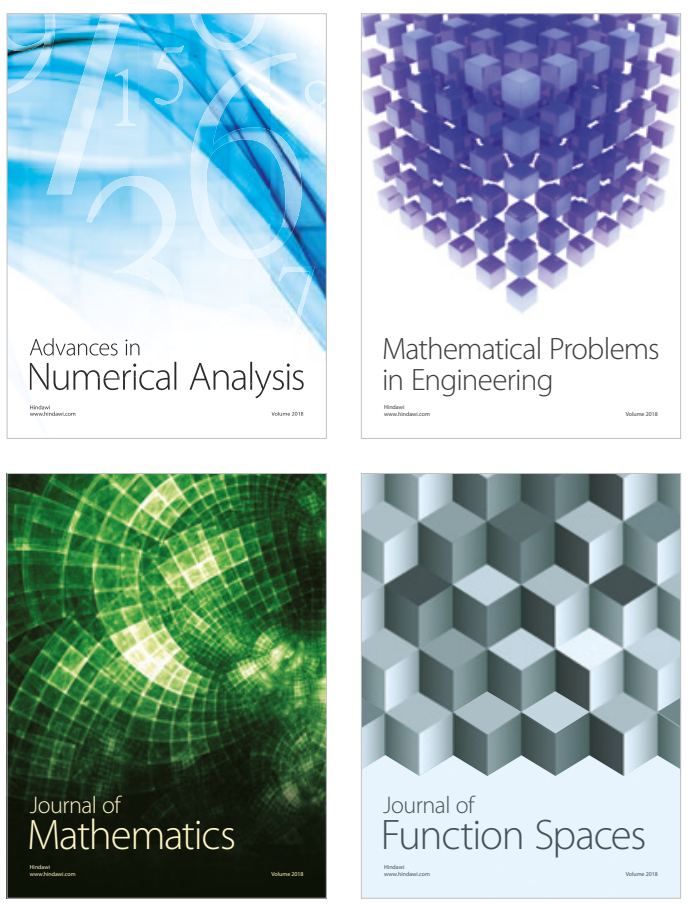

Mathematical Problems in Engineering

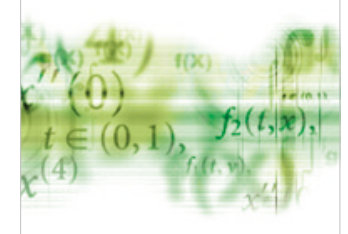

International Journal of

Differential Equations

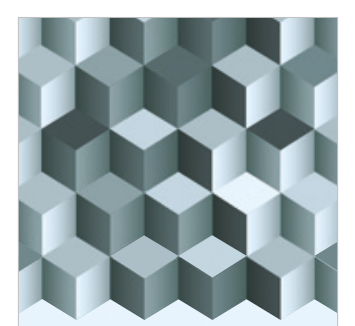

Journal of

Function Spaces

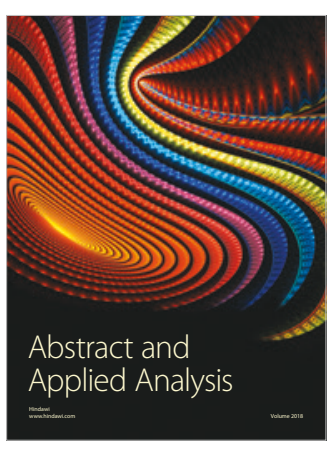

The Scientific

World Journal

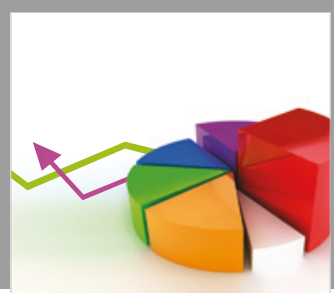

Journal of

Probability and Statistics
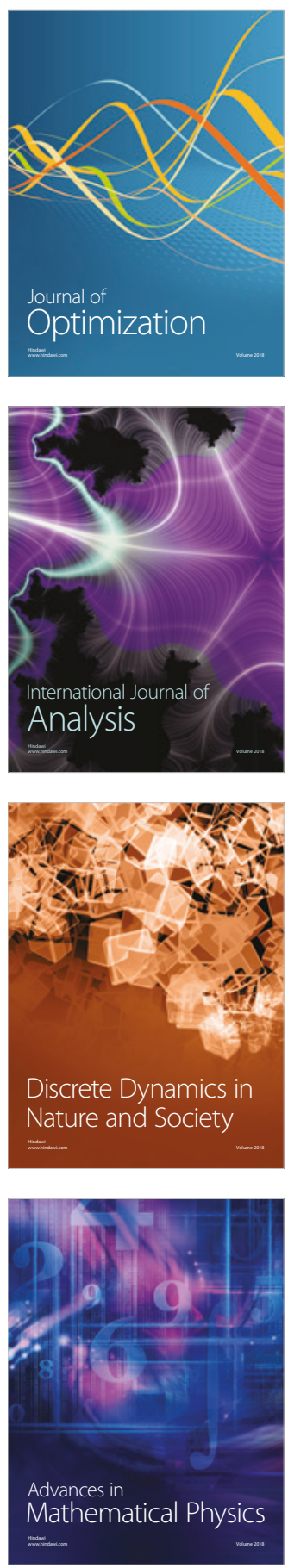